\title{
Acute gout and the accident and emergency department
}

\author{
R. H. HARDY AND B. NATION \\ Department of Accident and Emergency Medicine, Hereford General Hospital, and \\ Department of Pathology, Hereford County Hospital, Hereford
}

\section{INTRODUCTION}

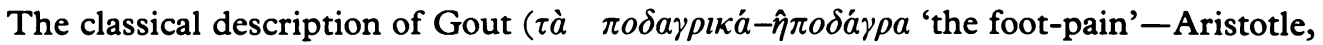
$350 \mathrm{BC}$; Hippocrates, $430 \mathrm{BC}$ ) suggests that the earliest references were to the characteristic crystal synovitis of the first metatarsophalangeal joint. Antoni van Leuwenhoek published a beautiful drawing of urate crystals from a tophus in 1679 . Since that time the term 'gout' has been applied to an increasingly vague and ill-defined collection of inflammatory diseases reaching a peak of confusion in the eighteenth century. By that time it had become almost entirely non-specific. There are innumerable articles on 'gout' and urate metabolism and a few about 'pseudo-gout' among them, but there are three or four which stand out as light-houses to the bewildered explorer: Professor George Nuki's review article of purine metabolism and crystal disease of connective tissue is interesting on its own account and has 135 references to the literature (Nuki, 1971). Alexander Gutman's review of the whole field of gout is masterly and equates 'gout' with a state of hyperuricaemia, however caused (Gutman, 1973). This assumption is almost universal. Edward W. Holmes's contribution however concedes that not all cases of acute gout present with a raised serum uric acid but goes on to say that 'hyperuricaemia is manifested at sometime in $98 \%$ of individuals with gout' (1977). Finally, a review article in the British Medical Journal describes contemporary work on the role of leucocytes in the pathogenesis of the acute attack of crystal synovitis (1973). 'Gout' is in essence a disorder of purine metabolism leading to deposits of urate crystal in the synovium, or peri-articular connective tissues. 'Pseudo-gout' or pyrophosphate arthropathy describes the acute synovitis due to deposition of calcium pyrophosphate in a joint. This article limits itself to those cases proved by crystalloscopy to be 'gout'. The term 'tophaceous disease' is used when urate deposition has produced tophi but not synovitis.

Correspondence: $\operatorname{Dr}$ R. H. Hardy, Department of Accident and Emergency Medicine, Hereford General Hospital, Nelson Street, Hereford 


\section{METHOD}

A method of small joint aspiration was developed using local infiltration of skin and joint capsule with lignocaine, and a $25 \mathrm{G}$ needle introduced under image-intensified fluoroscopy. The needle was left in the joint and abundant aspirate withdrawn into dry, sterile syringe. If the amount of joint fluid was scanty Haemaccel was used to wash out any possible crystalline material $(0.5 \mathrm{ml}$ of eluent for an interphalangeal joint) and the aspirate submitted for crystalloscopy and gram-stain.

Polarized crystalloscopy of urate and calcium pyrophosphate demonstrates the difference in crystal morphology.

Compensated polarization is achieved by inserting a red compensator into the microscope; this demonstrates the difference in crystal birefringence. Urate crystalsshow strong negative birefringence; the crystals are yellow when parallel to the slow岕 direction and blue when perpendicular. They are characteristically needle-shaped.

Calcium pyrophosphate crystals show weak positive birefringence; the crystals are. blue when parallel to the slow direction and yellow when perpendicular. The crystalsio have the appearance of pleomorphic granules.

\section{RESULTS}

In a period of just over 6 years in a large rural accident and emergency unit 131 patients $\vec{\circ}$ were recorded as presenting themselves with symptoms and signs suggestive of actofes gout. This is $0 \cdot 1 \%$ of the total of new patients seen during this period $(130000)$. Thesesto were diagnosed on the basis of two main presentations (1) acute inflammatory jo disease; or (2) acute tophaceous disease, both with intense pain, worse at night $\vec{\Omega}_{\tilde{N}}$ accompanied by local heat, swelling, redness and tenderness/pain but no rise of bodyo temperature. In chronic tophaceous disease skin breakdown was the main presenting sign.

In retrospect, 23 of these diagnoses were suspect. Of the 108 clinically probable diagnoses of gout a joint aspirate or tophaceous deposit was obtained of sufficient: amount to allow polaroscopy in 38 . Of those $38,22(58 \%)$ gave positive findings of monosodium urate crystals and $5(13 \%)$ of calcium pyrophosphate crystals. In theremaining $11(29 \%)$ crystalloscopy was negative for both types of crystal. Of the 22 crystalloscopies positive for urate $11(50 \%)$ showed a normal serum 'uric acid' and 80 $(36 \%)$ showed a rise of 'uric acid' in the serum. Three specimens were lost in transit.

Only one case (male aged 71) showed positive results for both crystal synovitis and acute tophaceous disease simultaneously and the uric acid level was normal at $282 \mu \mathrm{mol} / \mathrm{s}$ 1. Of the cases of purely tophaceous disease three were referred as acute bacteria? abscesses by their family doctor and one was a member of the nursing staff in the unit who had a chronic painless lump on the radial border of an index finger exactly halfway: between the metacarpo-phalangeal and proximal interphalangeal joints-as far from aw joint as it is possible to get in a finger, and confined to the thickness of the skin. Relief of acute synovitis by lavage with Haemaccel was dramatic-all symptoms being relieved? after the period of local anaesthesia for lavage and disappearing within $48 \mathrm{~h}$. This effecten was not entirely specific in that it has been noticed in patients with acute synovitis due too other causes than monosodium urate or calcium pyrophosphate. 
Table 1 Summary of findings in 22 patients suffering from connective tissue disease due to deposition of monosodium urate crystals proved by crystalloscopy

\begin{tabular}{|c|c|c|c|c|}
\hline \multirow[b]{2}{*}{ Sex } & \multirow{2}{*}{$\begin{array}{c}\text { Tophaceous } \\
\text { disease }\end{array}$} & \multirow{2}{*}{$\begin{array}{l}\text { Crystal } \\
\text { synovitis }\end{array}$} & \multicolumn{2}{|c|}{ Serum uric acid } \\
\hline & & & Raised & Normal \\
\hline M & $\sqrt{ }$ & & 632 & \\
\hline F & & $\sqrt{ }$ & & 450 \\
\hline$M$ & & $\sqrt{ }$ & & 467 \\
\hline $\mathrm{F}$ & & $\sqrt{ }$ & 533 & \\
\hline$M$ & & $\checkmark$ & & \\
\hline$F$ & $\checkmark$ & & & 219 \\
\hline$M$ & $\checkmark$ & & & 414 \\
\hline$M$ & & $\sqrt{ }$ & 524 & \\
\hline$M$ & & $\sqrt{ }$ & & 506 \\
\hline$M$ & & $\sqrt{ }$ & & 513 \\
\hline$M$ & & $\sqrt{ }$ & & 510 \\
\hline M & & v & & 419 \\
\hline M & $\checkmark$ & & & \\
\hline $\mathrm{F}$ & $\checkmark$ & & 556 & \\
\hline M & & $\sqrt{ }$ & & 473 \\
\hline M & & $\sqrt{ }$ & & \\
\hline$M$ & $\sqrt{ }$ & $\checkmark$ & & 283 \\
\hline M & & $\checkmark$ & 611 & \\
\hline M & 2 & & & 422 \\
\hline M & & $\sqrt{ }$ & 596 & \\
\hline $\mathrm{F}$ & & $\checkmark$ & 472 & \\
\hline $\mathrm{F}$ & $\sqrt{ }$ & & 515 & \\
\hline
\end{tabular}

Serum uric acid-upper limit of normal for men $\quad 520 \mu \mathrm{gm} / 1$ upper limit of normal for women $450 \mu \mathrm{gm} / 1$

Table 2 Summary of totals from Table 1

No. of patients

\begin{tabular}{lr}
\hline Males & 16 \\
Females & 6 \\
Tophaceous disease & 8 \\
Crystal synovitis & 15 \\
Tophaceous disease and crystal synovitis & 1 \\
Raised serum uric acid & 8 \\
Normal serum uric acid & 11 \\
No result & 3
\end{tabular}


Table 3 Observations from single patients, not included in preceding tables, giving dramatic point to the dissociation of the level of serum uric acid from the diagnosis of the type of crystal synovitis

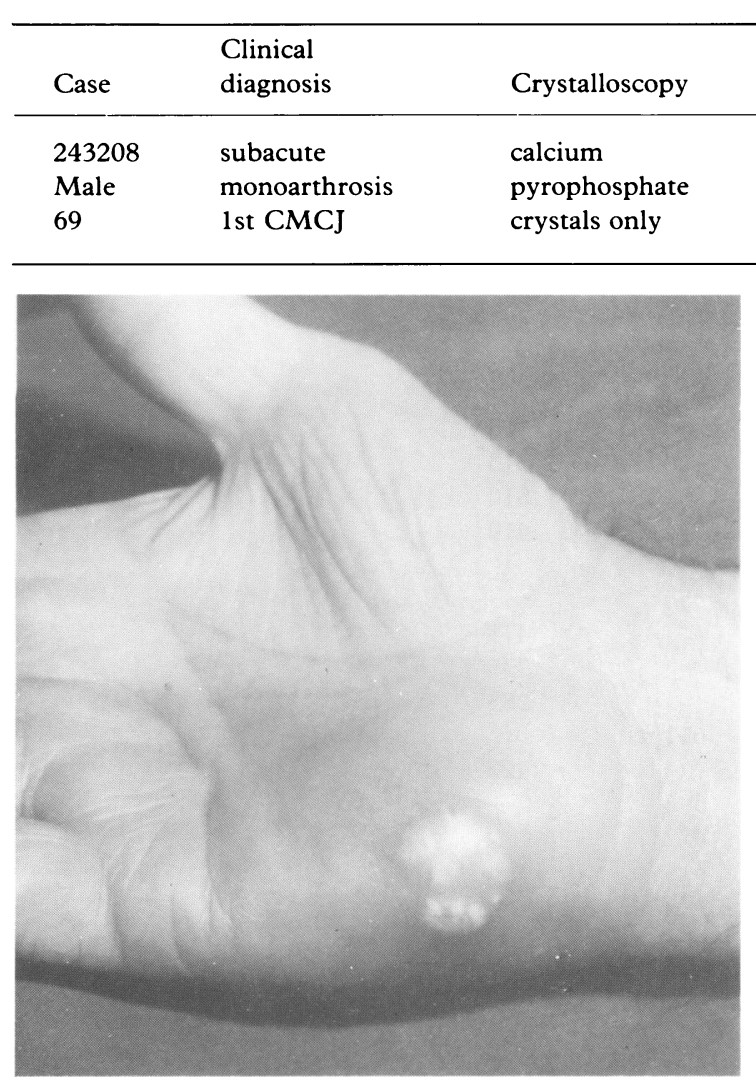

\begin{tabular}{|c|c|}
\hline $\begin{array}{l}\text { Serum } \\
\text { uric acid }\end{array}$ & $\begin{array}{l}\text { Aspirate } \\
\text { uric acid }\end{array}$ \\
\hline $\begin{array}{l}543 \mu \mathrm{mol} / 1 \\
(520)\end{array}$ & $<50 \mu \mathrm{mol} / 1$ \\
\hline
\end{tabular}

Fig. 1 Acute hypothenar tophus $(48 \mathrm{~h})$ \& presented as a bacterial abscess.

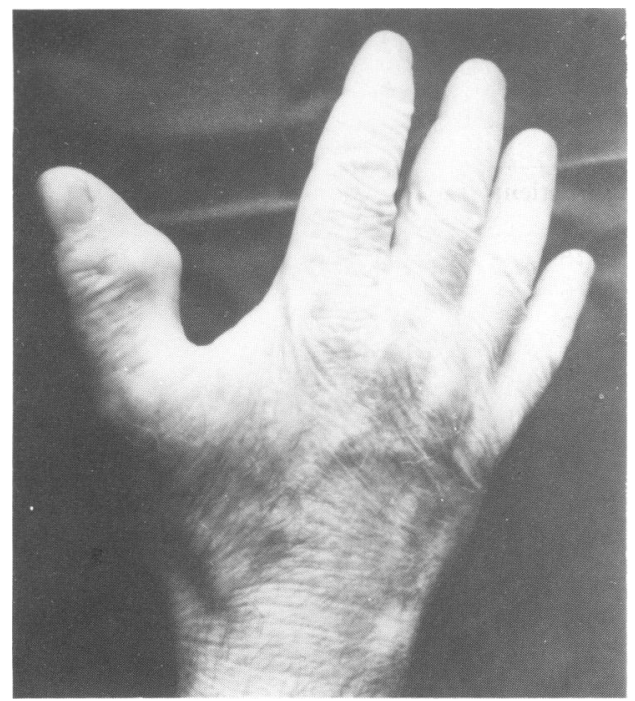

Fig. 2 Subacute pollical tophi ( $<10$ days) presented as a bacterial abscess. 


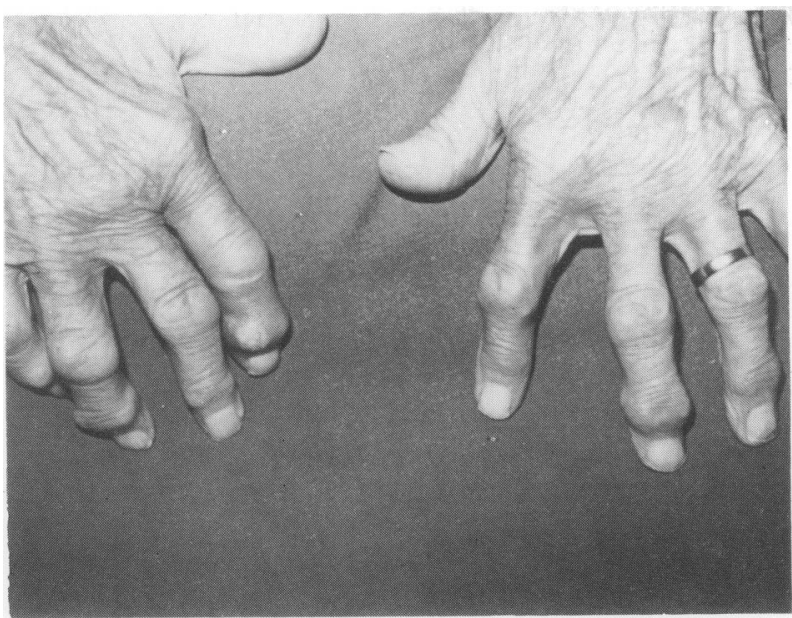

Fig. 3 Chronic tophaceous disease-the right index showing a tophus with severe pain and imminent skin breakdown.

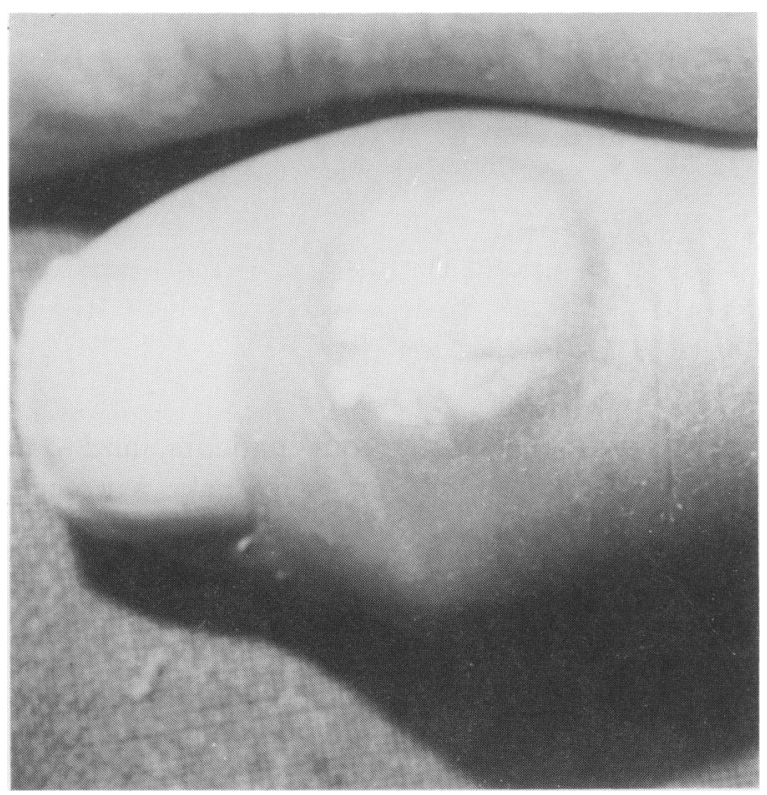

Fig. 4 Close-up view of the same lesion.

으 


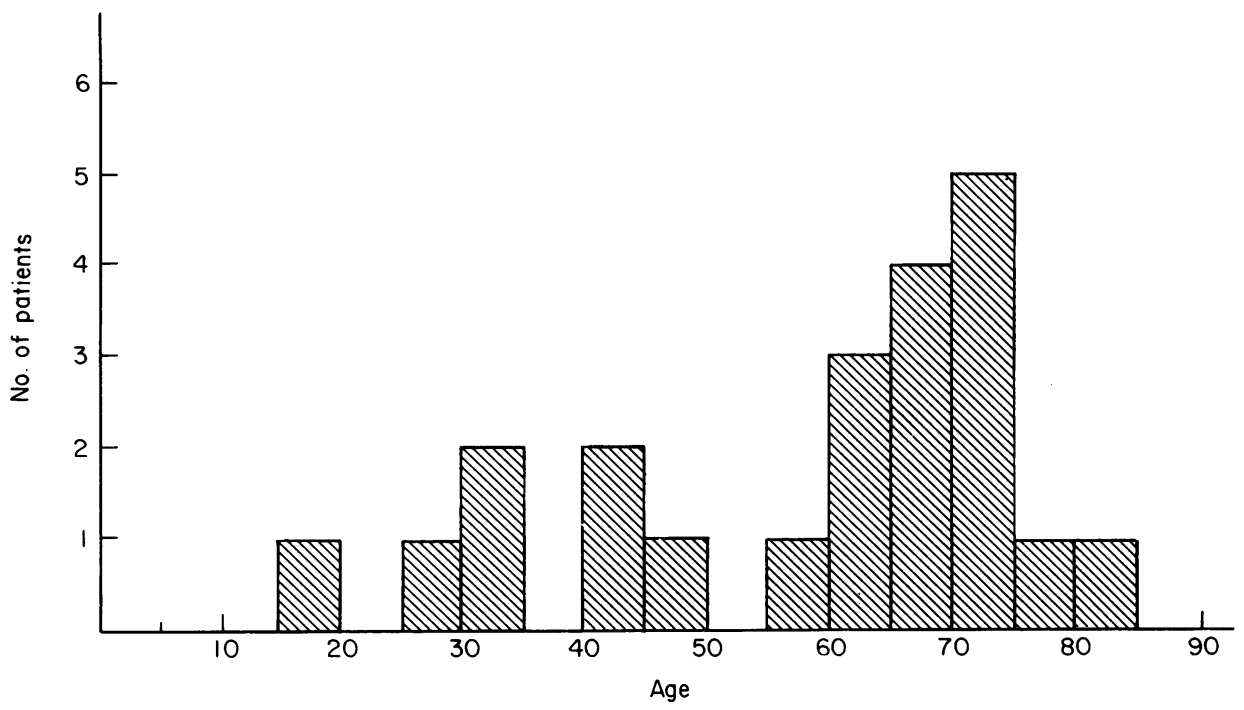

Fig. 5 Mean age of patients with disease of connective tissue due to deposition of monosodium urate crystals. When the serum uric acid was raised the mean age was 59.4 years (8 patients; $42 \%)$ and when normal was 57.4 years (11 patients; $58 \%$ ).

\section{DISCUSSION}

As casualty officers we have three primary obligations to our patients, and on $\overrightarrow{\vec{e}}$ secondary one. Our first is to relieve symptoms; our second is to make a precise diagnosis (these two may have to exchange priorities according to circumstances); out third is to restore function, and the fourth (an obligation of the second order) is tprevent recurrence. These are still our ethical goals as they were in the time Hippocrates and it ill becomes us to forget them. They apply whether our patient suffering from cardiac arrest, circular saw injury, road traffic accident or gout. Thesi results show that the diagnosis of gout in an accident and emergency department is problem although not necessarily a common one. Distinguishing gout from acute sepsis and other acute monarthroses is difficult and a knowledge of the serum uric acid is not often helpful. Only the isolation of urate crystals is conclusive.

As if to cast the apple of discord more dramatically into the arena of clarification recent patient presented with a sub-acute monarthrosis of the thumb, a raised serum uric acid and calcium pyrophosphate crystals in the aspirate. This polaroscopic finding was confirmed by biochemical micro-analysis. A sufficient source of confusion to the most devoted taxonomist. (Table 3). Aspiration can be a simple procedure for the accident and emergency department and we have particularly found the use of Haemaccel as an eluent most satisfactory. This has had the added advantage of rapig pain relief in most cases. 


\section{REFERENCES}

Aristotle (350 BC) Historia Animalium 8.22.2.

Gutman A. B. (1973) Gout: progress and present status. Arthritis and Rheumatism 16, 431-45.

Hippocrates (430 BC) Aphorisims 1254.

Holmes E. W. (1977) Pathogenesis of hyperuricaemia in primary gout. Clinical Rheumatic Diseases 3, 3.

Mechanism of Gouty Inflammations (1973) British Medical fournal 4, 125.

Nuki G. (1971) Crystals, Arthritis and Connective Tissue. Advanced medicine 15, 138.

Received 1 November 1983; editorial comments to authors 14 December 1983; accepted for publication 5 fanuary 1984

This paper was presented at the Scientific Meeting of the Emergency Medicine Research Society, 9-10 September 1983 in York. 